Int. Agrophys., 2022, 36, 27-35

INTERNATIONAL

\title{
Development of a machine vision system for the determination of some of the physical properties of very irregular small biomaterials
}

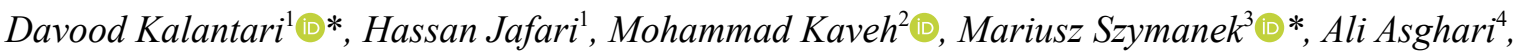 \\ Andrzej Marczuk ${ }^{3}$, and Esmail Khalife ${ }^{5}$ \\ ${ }^{1}$ Department of Biosystems Engineering, Sari Agricultural Sciences and Natural Resources University, Sari, \\ 9th km of Farah Abad Road, 4818168984, Iran \\ ${ }^{2}$ Department of Petroleum Engineering, College of Engineering, Knowledge University, 44001 Erbil, Iraq \\ ${ }^{3}$ Department of Agricultural, Forest and Transport Machinery, University of Life Sciences in Lublin, \\ Głęboka 28, 20-612 Lublin, Poland \\ ${ }^{4}$ Department of Biosystems Engineering, Gorgan Agricultural and Natural Resources University, Iran \\ ${ }^{5}$ Department of Civil Engineering, Cihan University-Erbil, Kurdistan Region, Erbil 44001, Iraq
}

Received September 17, 2021; accepted January 18, 2022

\begin{abstract}
The application of an image processing technique is presented for the volume estimation of very irregular small biomaterials (wheat and rice-paddy grains). Two common cylindrical small biomaterials, the Alvand variety of wheat grain and the Neda variety of paddy grain were considered for examination. The captured images were exported to be processed by an image processing software (ImageJ) and the edge-extracted image was used in SolidWorks for the $3 \mathrm{D}$ reconstruction of the model. The revolved images in the SolidWork were used to estimate the volume of the examined grains. The estimated volume was then compared with the conventional mathematical expression and also with the real volume measurement using the fluid displacement method. Volume estimation using machine vision and image processing techniques has a considerably lower mean error $(9.5 \%)$ in comparison to the mathematical error $(14.7 \%)$. The average value of cylindricity for Alvand wheat was found to be equal to $82.34 \%$ at a moisture content of $11.83 \%$. The new cylindricity factor had a significantly smaller standard deviation in comparison to the standard deviation of the sphericity factor for the examined cylindrical crops $(61.5 \%$ for the wheat grains and $59.6 \%$ for the paddy grains). The new cylindricity factor can be used for the heat and mass transfer modelling of cylindrical crops.

Keywords: machine vision, physical properties, volume, image processing, ImageJ, sphericity
\end{abstract}

*Corresponding author e-mail: mariusz.szymanek@up.lublin.pl d.kalantari@sanru.ac.ir

\section{INTRODUCTION}

Huge postharvest losses occur in the handling and processing of high-quality food products and biomaterials due to the non-optimized design of certain equipment (Narendra et al., 2010). Cereals are one of the most prominent nutrition materials in Iranian food consumption. More than 50 percent of the nutrition material for each Iranian is provided by different kinds of breads (Mirasi et al., 2014). Therefore, a knowledge of the physical properties of the cereals is necessary for manufacturing optimized devices for handling, cleaning, conveying, storing and milling (Unal, 2009; Kalantari, 2016; Kalantari and Eshtavad, 2013).

An understanding of the aero- and hydrodynamic properties of agricultural products is required for the movement of biomaterials by water or air and the separation of foreign materials from them. The density, shape and drag coefficient are the physical properties required to calculate the terminal velocity of an object in a fluid. In air transport or pneumatic separation, the air velocity is greater than the terminal velocity of the object. Moreover, for small biomaterials such as grains to descend slowly, the air velocity must be slightly lower than the terminal velocity.

(C) 2022 Institute of Agrophysics, Polish Academy of Sciences 
Therefore, the shape of the biological material, i.e., spherical or cylindrical, has a very important role to play in grain flow through the discharge gates of silos and grain drills, as well as determining the air flow around the grains during movement which in turn allows for the determination of the drag coefficient (Chen et al., 2020; Kalantari, 2016; Dziki and Laskowski, 2005).

For most cereals, the bulk porosity is between 35 and $55 \%$; therefore the porous nature of the grain mass provides the possibility that in the blowing and drying process, almost all of the grains are in contact with air (Navarro and Noyes, 2002). Another important physical property of agricultural crops and materials is volume, which is an important parameter in the mass transfer and heat transfer of these biomaterials. Several mathematical expressions have been proposed for computing and estimating the volume of irregular materials (e.g., Kheiralipour et al., 2008; Unal 2009; El Fawal et al., 2009). As an example, the temperature rise of a biomaterial, e.g., a cereal grain in a microwave field is equal to Eq. (1) (Jafari et al., 2018):

$$
\Delta T=\frac{P_{e} \Delta t}{4.18 \rho_{s} C V},
$$

where: $\Delta T$ is the temperature rise $\left({ }^{\circ} \mathrm{C}\right), P_{e}$ is microwave power (W), $\Delta t$ is the heating time (s), $C$ is the specific heat of the dielectric material $\left(\mathrm{Cal} \mathrm{g}^{-1}{ }^{\circ} \mathrm{C}^{-1}\right), \rho_{s}$ is the grain density $\left(\mathrm{g} \mathrm{mm}^{-3}\right)$ and $V$ is the grain volume $\left(\mathrm{mm}^{3}\right)$, (Vongpradubchai and Rattanadecho, 2009; Jafari et al., 2018). In this expression the influence of grain volume and density is evident of a temperature rise and consequently the evaporation rate and drying kinetics. Meanwhile, the volume and uniformity of the volume, i.e., sphericity or cylindricity are important physical properties that consumers use to buy crops or fruits according to their tastes. In other research, Apinyavisit et al. (2018) reported that microwave absorption varies with shape change during the drying of longan fruit. They considered two adjusting correction factors in the microwave absorption equation to consider the shape variation from regular geometry to irregular during the drying process. Also, several other attempts have been made for the mass determination of agricultural crops based on their volume, since in most agricultural crops, density changes are relatively minor (Forbes, 2000; Araujo et al., 2020). Bulk density, true density, and porosity are useful parameters in designing grain hoppers, determining grain flow characteristics and optimizing storage facilities, e.g., Kalantari (2016). For example, the thousand grain weight of grains is used for calculating the head yield (Unal, 2009).

The application of computer imaging to food processing fields was first introduced in 1989 for the purposes of grain quality inspection (Zayas et al., 1986). Image processing techniques can be useful in the accurate and rapid quality determination of food products (Saini et al., 2012; Pourdarbani et al., 2020; Sabzi et al., 2020). The various external attributes of agricultural products are the key factors in designing sorting machines; therefore their size, shape and colour are commonly used in commercial sorting, e.g. Xie et al. (2019), Chen et al. (2020). However, the possibility of detecting external defects still remains open for further investigation (Da Costa et al., 2020). Three different methods to measure the volume of materials were reported and evaluated in the literature (Tabatabaeefar, 2003; Dziki and Laskowski, 2005; Demirbas and Dursun, 2007; Varnamkhasti et al., 2007; Al-Mahasneh and Rababah, 2007). The methods included fluid volume displacements, mathematical models, and image processing techniques (3D-reconstructed model) for large agricultural products.

A considerable amount of research may be extracted from literature regarding the application of image processing techniques used to estimate the geometrical properties of both regular and irregular materials and also biomaterials such as volume, surface area, surface characteristics, sphericity, etc. (Aldalur et al., 2019; Rashidi et al., 2007; Sadrnia et al., 2007; Bulent Koc, 2007; Wang and Nguang, 2007; Khojastehnazhand et al., 2008; Arjenaki et al., 2012). However, research that illustrates the capabilities of image processing techniques to estimate the accurate volume of irregular small objects like grains and cereals is comparatively rare. Therefore, the main aim of this investigation is to employ image processing techniques using ImageJ software together with engineering software (Solidworks) for the volume estimation of very irregular small biomaterials, i.e., grain cereals. In the next step, a comparison between the volume obtained via $3 \mathrm{D}$ modelling with a mathematical equation and the fluid displacement method is presented as a final conclusion for indicating the capability of the employed technique for volume measurements on a small scale. Finally, a new parameter is introduced for cylindrical biomaterials, such as wheat grains and paddies which is called "cylindricity". This parameter may be important in the postharvest processing of biomaterials such as separating the grain from the cluster, drying, cleaning, sorting, grading and also heat and mass transfer modelling.

\section{MATERIAL AND METHODS}

Due to the introduction of the new parameter of "cylindricity" in this study, we used two common cylindrical small biomaterials, i.e., wheat grain and paddy grain for the investigation. Therefore, some physical properties of the Alvand variety of wheat grains and the Neda variety of paddy grain were measured or calculated, these values are summarized in Tables 1 and 2.

In order to determine the moisture content of the samples, three groups of $10 \mathrm{~g}$ samples were placed in a laboratory oven for $19 \mathrm{~h}$ at 130 temperature. The wet-based moisture content of the samples was then calculated using Eq. (2) (Kaveh et al., 2021): 
Table 1. Measured physical properties of Alvand wheat at $11.83 \%$ moisture content

\begin{tabular}{|c|c|c|c|c|c|c|}
\hline Physical properties & Symbol & Replication & Average & $\begin{array}{l}\text { Standard } \\
\text { deviation }\end{array}$ & Maximum & Minimum \\
\hline Length (mm) & $L$ & 25 & 6.96 & 0.49 & 7.80 & 6.30 \\
\hline Width (mm) & $W$ & 25 & 3.49 & 0.35 & 4.35 & 2.85 \\
\hline Thickness (mm) & $T$ & 25 & 3.03 & 0.36 & 3.90 & 2.40 \\
\hline Geometric mean diameter (mm) & $D_{g}$ & 25 & 4.18 & 0.27 & 4.72 & 3.69 \\
\hline Sphericity (\%) & $\phi$ & 25 & 60.34 & 5.48 & 73.55 & 48.83 \\
\hline Cylindricity (\%) & $\psi$ & 25 & 82.34 & 2.11 & 86.29 & 77.41 \\
\hline Intermediate aspect ratio & $n$ & 25 & 0.47 & 0.06 & 0.63 & 0.34 \\
\hline Surface area $\left(\mathrm{mm}^{2}\right)$ & $S$ & 25 & 46.33 & 5.44 & 59.15 & 36.72 \\
\hline Bulk density $\left(\mathrm{kg} \mathrm{m}^{-3}\right)$ & $\rho_{b}$ & 3 & 636.85 & 1.40 & 638.33 & 635.55 \\
\hline Real density $\left(\mathrm{kg} \mathrm{m}^{-3}\right)$ & $\rho_{p}$ & 3 & 1243.59 & 11.10 & 1250.00 & 1230.77 \\
\hline Porosity (\%) & $P$ & 3 & 48.79 & 0.46 & 49.15 & 48.27 \\
\hline Weight of 1000 grains (g) & $m$ & 3 & 37.25 & 0.60 & 36.80 & 37.93 \\
\hline
\end{tabular}

Table 2. Measured physical properties of Neda paddy grain at $12.33 \%$ moisture content

\begin{tabular}{|c|c|c|c|c|c|c|}
\hline Physical properties & Symbol & Replication & Average & $\begin{array}{l}\text { Standard } \\
\text { deviation }\end{array}$ & Maximum & Minimum \\
\hline Length (mm) & $L$ & 25 & 9.37 & 0.41 & 10.09 & 8.23 \\
\hline Width (mm) & $W$ & 25 & 2.59 & 0.26 & 3.12 & 2 \\
\hline Thickness(mm) & $T$ & 25 & 2.12 & 0.17 & 2.43 & 1.88 \\
\hline Geometric mean diameter (mm) & $D_{g}$ & 25 & 3.71 & 0.21 & 4.21 & 3.25 \\
\hline Sphericity (\%) & $\phi$ & 25 & 39.65 & 2.23 & 43.74 & 35.55 \\
\hline Cylindricity (\%) & $\psi$ & 25 & 90.03 & 0.90 & 91.74 & 88.35 \\
\hline Intermediate aspect ratio & $n$ & 25 & 0.25 & 0.02 & 0.29 & 0.21 \\
\hline Surface area $\left(\mathrm{mm}^{2}\right)$ & $S$ & 25 & 39.42 & 4.10 & 49.48 & 31.17 \\
\hline Bulk density $\left(\mathrm{kg} \mathrm{m}^{-3}\right)$ & $\rho_{b}$ & 3 & 613.45 & 11.35 & 634.25 & 602.36 \\
\hline Real density $\left(\mathrm{kg} \mathrm{m}^{-3}\right)$ & $\rho_{p}$ & 3 & 1471.70 & 10.12 & 1495.35 & 1435.36 \\
\hline Porosity (\%) & $P$ & 3 & 55.69 & 0.59 & 60.12 & 52.43 \\
\hline Weight of 1000 grains (g) & $m$ & 3 & 27.2 & 1.23 & 30.14 & 26.42 \\
\hline
\end{tabular}

$$
W(w b)=\frac{W_{i}-W_{d}}{W_{i}} 100,
$$

where: $W(w b)(-)$ is the wet-based moisture content of the sample, $W_{i}$ is the initial weight of the sample $(\mathrm{g})$ and $W_{d}$ is the weight of the dried sample (g).

In order to calculate the particle density of the wheat and paddy $\left(\rho_{p}\right)$, a certain weight of the seeds was soaked in toluene. The average particle volume of the seeds was calculated by measuring the displaced toluene volume in a scaled burette (Mohsenin, 1978; Razavi and Akbari, 2011). In order to determine the bulk density of the wheat and paddy grains $\left(\rho_{b}\right)$, a cylindrical container was filled with grains by dropping the grains uniformly from a height of $20 \mathrm{~cm}$ into the container. Then the top surface of the grains was smoothed using a blade. Their bulk density was then determined by dividing the weight of the grains by the container volume. After calculating the particle and bulk densities of the grains, the porosity of the samples may be obtained. A simplified expression for calculating the porosity has already was given by (Mohsenin, 1978; Mustafa, 2007) in the form of:

$$
\varepsilon=\left(1-\frac{\rho_{b}}{\rho_{p}}\right) 100,
$$

where: $\varepsilon(-)$ is the porosity of the grains (\%), $\rho_{b}$ is the bulk density $\left(\mathrm{kg} \mathrm{m}^{-3}\right)$ and $\rho_{p}$ is the grain density $\left(\mathrm{kg} \mathrm{m}^{-3}\right)$.

In the next step, a stereomicroscope device (Nikon, SMZ-U) was used to measure the minor, intermediate and major diameters of 25 randomly selected wheat and paddy grains. The dimensions were observed and recorded using 
a scaled ocular installed on the stereomicroscope. Also, photos of the grains were taken using a digital camera installed on the stereomicroscope.

The geometric mean diameter, $D_{g}(\mathrm{~mm})$, was calculated using Eq. (4) (Chayjan et al., 2017; Kiani et al., 2008; Shkelqim et al., 2010):

$$
D_{g}=(L W T)^{\frac{1}{3}},
$$

where: $L, W$, and $T(\mathrm{~mm})$ are the length (largest value), width (intermediate value) and thickness (minor diameter) of the measured irregular biomaterial, e.g., wheat seeds. For elliptical objects such as wheat, the sphericity, $\phi(-)$, was calculated using Eq. (5), (Mohsenin, 1978; Dursun and Dursun, 2005):

$$
\phi=\left[\frac{\left(\frac{\pi}{6}\right) L W T}{\left(\frac{\pi}{6}\right) L^{3}}\right\rfloor^{\frac{1}{3}}=\frac{(L W T)^{\frac{1}{3}}}{L} .
$$

The surface area of the wheat and paddy grains, $S\left(\mathrm{~mm}^{2}\right)$, was calculated using Eq. (6), (Al-Mahasneh and Rababah, 2007):

$$
S=\frac{\pi B L^{2}}{(2 L-B)} .
$$

In the above expression, $B(\mathrm{~mm})$ is a length scale defined by:

$$
B=\sqrt{W T} .
$$

The intermediate aspect ratio (rectangular ratio) was calculated using the following equation:

$$
n=\frac{W+T}{2 L} .
$$

Another physical parameter developed in this study is called "cylindricity", which can be used for some cylindrical crops, such as wheat and rice. Hence, if cylindricity tended to 1, the cylindrical coordinate will be easier to establish and specific for the corresponding crop.

The cylindricity, $\psi(-)$, is defined by the ratio of the volume of ellipse to the surrounding cylinder volume of the crop in the form of:

$$
\psi=\left\lfloor\left.\frac{\left(\frac{\pi}{6}\right) L W T}{\left(\frac{\pi}{16}\right)(W+T)^{2} L}\right|^{n}=\left[\frac{8 W T}{3(W+T)^{2}}\right]^{n} .\right.
$$

In which, $W$ is the width (mm), $T$ is the thickness (mm) and $n$ is the intermediate aspect ratio as defined by Eq. (8). In extreme conditions, if the crop tended towards long cylinder forms $(L \rightarrow \infty)$, the cylindericity will be equal to $\left.\lim _{L \rightarrow \infty}\left[\frac{8 W T}{3(W+T)^{2}}\right]\right]^{\left.\frac{W+T}{2+L}\right)}=1$.

The volume of each grain was measured in a $500 \mathrm{ml}$ micro tube by inserting the seed into acetone and tacking two photographic images, one with and one without the grain inside the micro tube (Figs 1 and 2). The microtubes

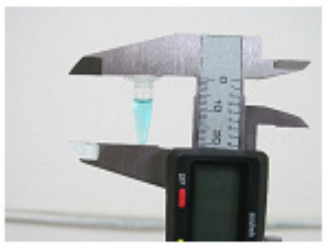

a

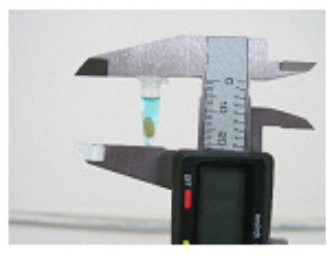

$\mathrm{b}$
Fig. 1. Micro tube: $a$ - without wheat grain, $b$ - with grain, both were used in this study to measure grain volume.

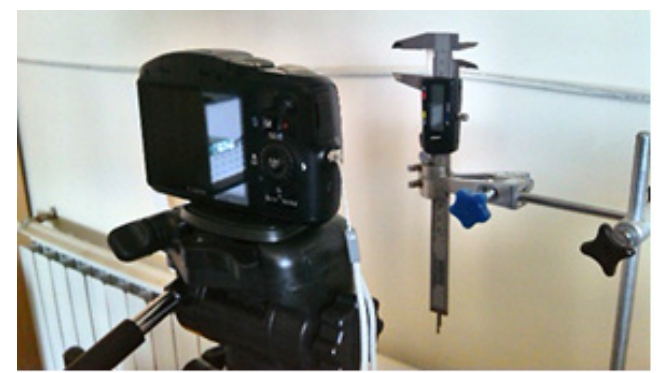

Fig. 2. Setup for the volume measurement used in this study.

were filled with 175 microlitres of acetone and colouring powder and fixed in a calliper. The wheat and paddy volume was then calculated by subtracting the two captured images, i.e., with and without the grain.

A more specific mathematical expression for estimating the volume of wheat grain was already proposed by Al-Mahasneh and Rababah (2007) in the form of:

$$
V=\frac{\pi B^{2} L^{2}}{6(2 L-B)},
$$

where: $V$ is grain volume $\left(\mathrm{mm}^{3}\right)$, and $B(\mathrm{~mm})$ is a length scale defined by Eq. (7).

In the current research, a 3D reconstructed model of the grain as an output of the image processing technique was used to estimate its volume. In this method, the images captured using a digital camera (canon SX150) were imported and processed using image processing software (ImageJ) to extract the edges (Fig. 3). The edge-extracted image was then exported to the Solidworks software. Finally, a 3D model was formed by revolving one half of the imported image about the longitudinal centre line (Fig. 4). The average of both of the revolving volumes was considered to be the estimated grain volume. However, some considerations concerning the edge detection in the captured images must be taken into account for a robust $3 \mathrm{D}$ reconstruction of the images.

\section{RESULTS AND DISCUSSION}

A summary of the physical properties investigated and measured in this study are listed in Tables 1 and 2. According to the results presented in Table 1, the intermediate length of this variety is $6.96 \mathrm{~mm}$ with a standard deviation of 

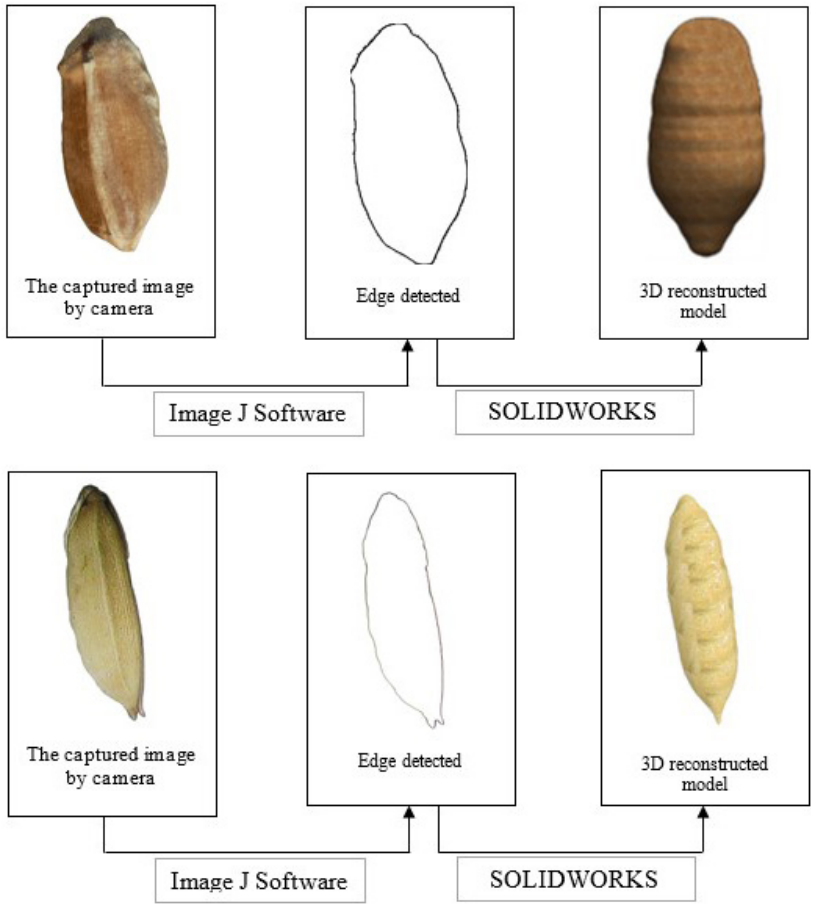

Fig. 3. Conversion steps: captured image to $3 \mathrm{D}$ reconstructed model.

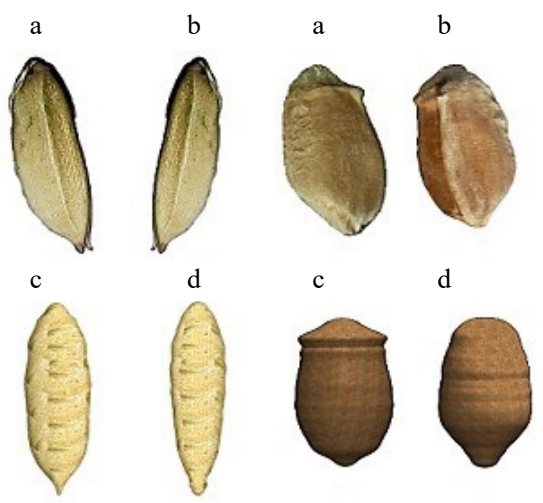

Fig. 4. Real image of paddy grain and wheat: $\mathrm{a}$ - front, $\mathrm{b}$ - back. 3D model made from half boundary revolving: $c$ - right-side revolving, $\mathrm{d}$ - left-side revolving.

Table 3. Wheat grain volume results from different methods

\begin{tabular}{lccccc}
\hline Volume estimation method & Replications & $\begin{array}{c}\text { Average } \\
\left(\mathrm{mm}^{3}\right)\end{array}$ & $\begin{array}{c}\text { Standard } \\
\text { deviation } \\
\left(\mathrm{mm}^{3}\right)\end{array}$ & $\begin{array}{c}\text { Error } \\
(\%)\end{array}$ & - \\
\hline Fluid displacement & 25 & 28.87 & 6.71 & - & 9.49 \\
3D model using machine Vision & 25 & 28.81 & 6.38 & 0.81 & 0.44 \\
Mathematical model & 25 & 25.31 & 5.2 & 14.69 \\
\hline
\end{tabular}

$0.49 \mathrm{~mm}$, it has a width of $3.49 \mathrm{~mm}$ with a standard deviation of $0.35 \mathrm{~mm}$, a thickness $3.03 \mathrm{~mm}$ with a standard deviation of $0.36 \mathrm{~mm}$. The geometric mean diameter is $4.18 \mathrm{~mm}$ with a standard deviation of $0.27 \mathrm{~mm}$, the mean sphericity is $60.34 \%$ with a standard deviation of $5.48 \%$, the intermediate aspect ratio (rectangle ratio) is 0.47 with a standard deviation of 0.06 , the surface area is $46.33 \mathrm{~mm}^{2}$ with a standard deviation of $5.44 \mathrm{~mm}^{2}$, the real density is $1243.59 \mathrm{~kg} \mathrm{~m}^{-3}$ with a standard deviation of $11.10 \mathrm{~kg} \mathrm{~m}^{-3}$, the bulk density is $636.85 \mathrm{~kg} \mathrm{~m}^{-3}$ with a standard deviation of $1.4 \mathrm{~kg} \mathrm{~m}^{-3}$, the porosity is $48.79 \%$ with a standard deviation of $0.46 \%$.

The calculated volume of the wheat and paddy grains were determined using Eq. (10), the 3D model based on the image processing technique and the fluid displacement methods are given in Tables 3 and 4, respectively. According to the results obtained in this study, the average volume of the wheat grains were found to be equal to $28.81 \mathrm{~mm}^{3}$ using 3D reconstructed images, $25.31 \mathrm{~mm}^{3}$ using mathematical Eq. (10), and $28.87 \mathrm{~mm}^{3}$ using the fluid displacement method (the exact value). According to the results shown in Table 3, the average error of the 3D reconstructed model and the mathematical expression were equal to 9.49 and $14.69 \%$, respectively. The same qualitative results for paddy grains are given in Table 4 . The results of the experiments conducted in this study indicate that the image processing technique has an acceptable level of agreement with the real measurements for the volume of wheat grain in comparison to the available mathematical models. This results in an agreement with the results of Araujo et al. (2020), which postulated that the volume estimation of Passion fruit seeds with the digital image processing method provides more reliable values as compared with the previously obtained correlations, mathematical methods and volume estimation based on the projected area or circularity.

Variations in the error of calculating the volume of 25 randomly chosen grains are illustrated in Fig. 5. Based on the results shown in this figure, the estimated volume by means of the mathematical expression show remarkable jumps from the average error, while also having a higher mean error in comparison to the image processing technique. The volume estimation using the $3 \mathrm{D}$ reconstructed images has a considerably lower mean error $(9.5 \%)$ in compare with the mathematical error (14.7\%). 
Table 4. Paddy grain volume results from different methods

\begin{tabular}{lccccr}
\hline Volume estimation method & Replications & $\begin{array}{c}\text { Average } \\
\left(\mathrm{mm}^{3}\right)\end{array}$ & $\begin{array}{c}\text { Standard } \\
\text { deviation } \\
\left(\mathrm{mm}^{3}\right)\end{array}$ & $\mathrm{R}^{2}$ & $\begin{array}{c}\text { Error } \\
(\%)\end{array}$ \\
\hline Fluid displacement & 25 & 25.37 & 5.17 & - & - \\
3D model using machine Vision & 25 & 24.64 & 5.65 & 0.70 & 10.57 \\
Mathematical model & 25 & 16.19 & 10.80 & 0.53 & 35.82 \\
\hline
\end{tabular}

a

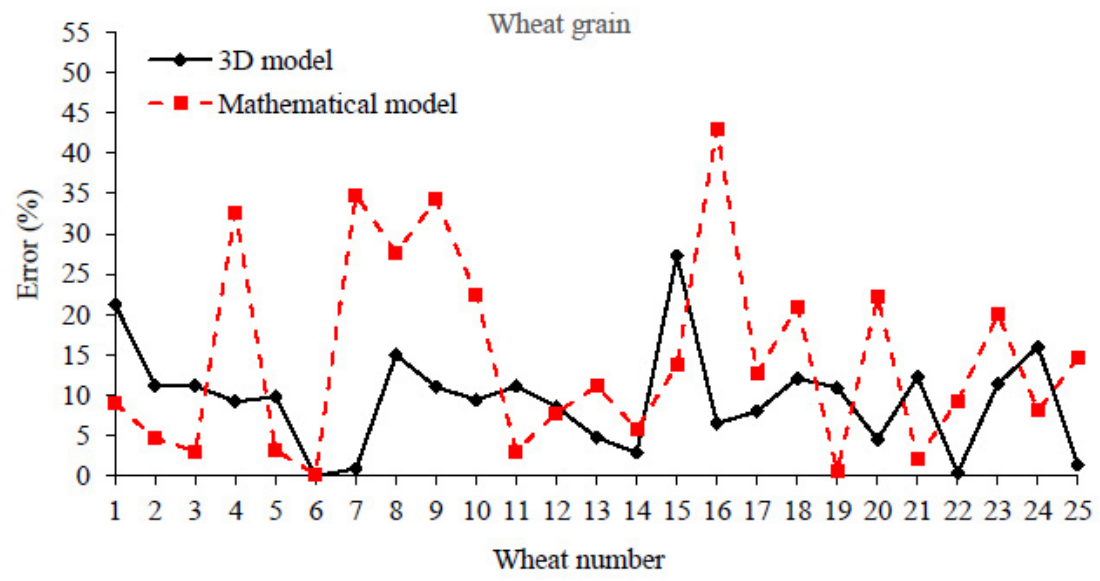

b

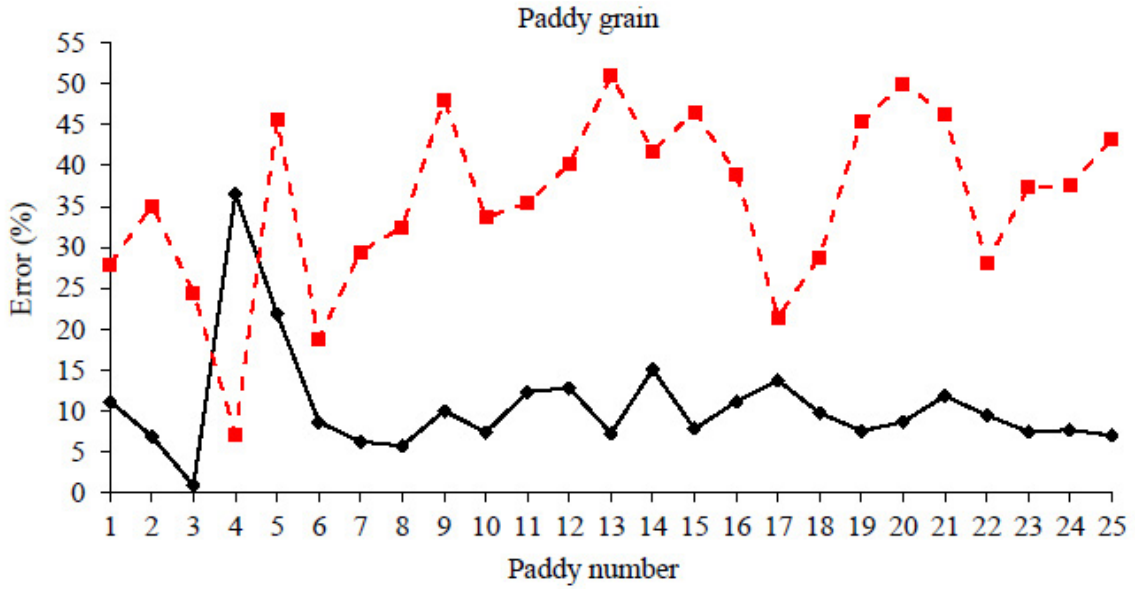

Fig. 5. Volume error by 3D modelling and mathematical computations (Eq. (9)) for: a - wheat grains and b - paddy grains.

As shown in Fig. 6, sphericity and cylindricity of the examined wheat samples have a linearly inverse relationship with each other. The statistical correlations between the sphericity and the cylindricity of the wheat grains and paddy grains are given in Eqs (11) and (12), respectively.

$$
\begin{gathered}
\psi=-0.380 \phi+105.3, \mathrm{R}^{2}=0.974, \\
\psi=-0.380 \phi+105.11, \mathrm{R}^{2}=0.884 .
\end{gathered}
$$

The average value of cylindricity for the Alvand wheat was found to be equal to $82.34 \%$ with a standard deviation of $2.11 \%$ at a moisture content of $11.83 \%$. Note that the obtained correlations (Eqs (11) and (12)) may not be valid for very long cylindrical objects, where their lengthto-diameter ratio tends to be very large. Investigations performed by Munder et al. (2017) indicated that the sphericity of sunflower seeds varies between 45 to $55 \%$. Using Eq. (11) shows that the cylindricity of sunflower seeds is approximately in the range of 88 to $84 \%$, respectively, thereby indicating that sunflower seeds should preferably be considered to have an equivalent cylindrical shape rather than a spherical one.

The large value for the cylindricity of the examined variety of wheat grains determines the appropriate modelling method of this biomaterial which should be based on a cylindrical coordinate system rather than a spherical coordinate. A knowledge of this information is important in 
a

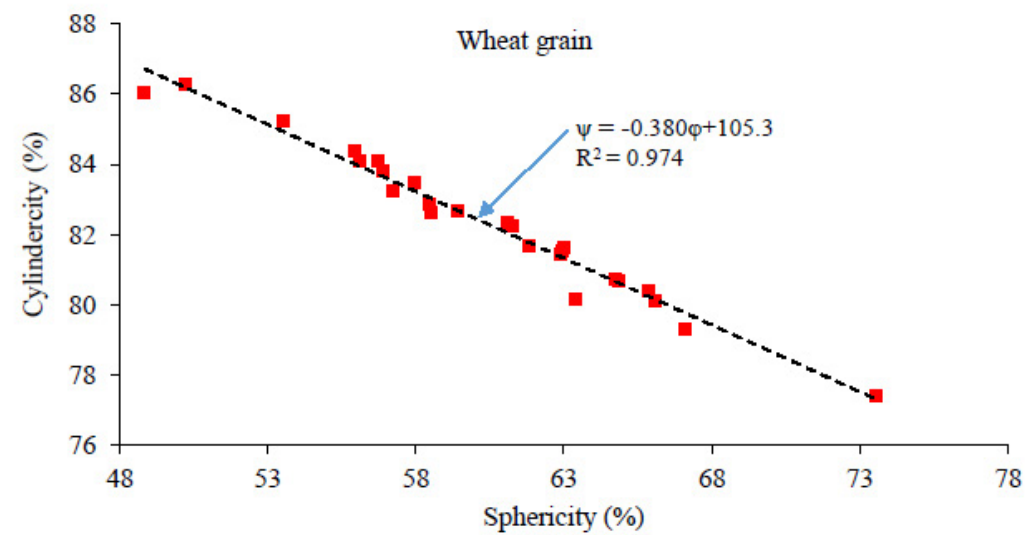

b

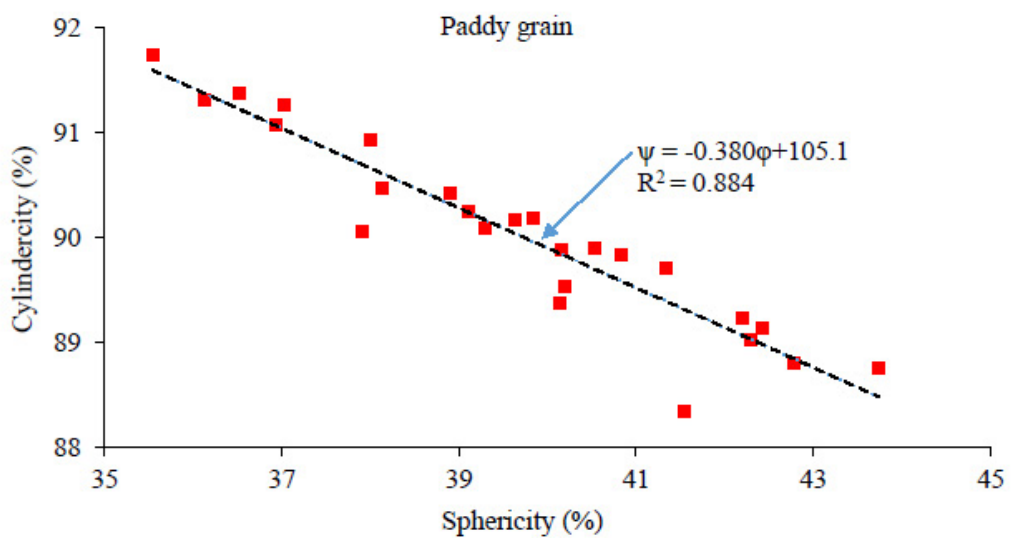

Fig. 6. Correlation between sphericity and cylindricity of the examined wheat and paddy samples: $a$ - wheat grains and $b$ - paddy grains.

the drag force estimation of grains or small biomaterials in cleaning, grading and separation processes (Solomon and Zewdu, 2009; and Araujo et al., 2020).

The cylindricity factor (Eq. (11)) may be used to assess considerations concerning aerodynamic properties in pneumatics conveyors and fluidized bed dryers, it is also useful for the heat and mass transfer modelling of such crops (Curcio and Maria, 2014). For example, the drag coefficients of grains vary with their shape, also, grains with a higher surface-to-volume may be dried faster (Mohsenin, 1978; and Razavi and Akbari, 2011). Khoshtaghaza and Chayjan (2007) reported that the shape factor, i.e., the sphericity or cylindricity of agricultural grains significantly affects fluidization stability and the fluidization pressure drop index (FPDI) of products during fluidized bed drying.

\section{CONCLUSIONS}

After performing the research described above, the following concluding remarks may be presented:

1. Correctly selecting the appropriate parameter in order to determine the geometric shape of crops and cereals, such as the spherical coefficient or the cylindrical coefficient (introduced in the present study) is of particular importance in the design of many items of agricultural equipment.
2. Three different methods of volume estimation were examined and evaluated in this study including $3 \mathrm{D}$ reconstruction of the captured images by means of the image processing technique (ImageJ) and the use of an engineering software (SolidWorks), conventional mathematical expression and real volume determination using the fluid displacement method.

3. The results obtained in this study indicated the capability and accuracy of image processing techniques in estimating the volume of very irregular small biomaterials.

4. The general correlation between the cylindricity and sphericity of a product may be written in the form of $\psi=-a \phi+b$, in which the correlation parameters $a$ and $b$ can be extracted from the experiments. Average values of $a=0.380$ and $b=105.2$ were obtained in this study for wheat and rice paddy grains.

5. The proposed "cylindricity" factor is a new physical property of cylindrical crops such as wheat, rice, sunflower grains and other similar materials. This factor can be used to determine the aerodynamic properties of small cylindrical biomaterials and also to model heat and mass transfer in such crops.

6 . The average values of " $a$ " and " $b$ " should be investigated for other cylindrical biomaterials and listed in a table in future research studies. 
Conflict of interest: The authors declare no conflict of interest.

\section{REFERENCES}

Aldalur A., Ángeles Bustamante M., and Barron L.J.R., 2019. Characterization of curd grain size and shape by 2-dimensional image analysis during the cheese making process in artisanal sheep dairies. J. Dairy Sci., 102(2), 1083-1095. https://doi.org/10.3168/jds.2018-15177.

Al-Mahasneh M.A., and Rababah T.M., 2007. Effect of moisture content on some physical properties of green wheat. J. Food Eng., 79, 1467-1473. https://doi.org/10.1016/j.jfoodeng.2006.04.045

Apinyavisit K., Nathakaranakule A., Mittal G.S., and Soponronnarit S., 2018. Heat and mass transfer properties of longan shrinking from a spherical to an irregular shape during drying. Biosys. Eng., 169, 11-21. https://doi. org/10.1016/j.biosystemseng.2018.01.007

Araujo M.E.V.D., Barbosa E.G., de Oliveira A.C.L., Milagres R.S., Pinto F.A.C., and Corrêa P.C., 2020. Physical properties of yellow passion fruit seeds (Passiflora edulis) during the drying process. Scientia Hort., 261, 109032. https://doi.org/10.1016/j.scienta.2019.109032

Arjenaki O.O., Moddares Motlagh A., and Ahmadi Moghaddam P., 2012. A new method for estimating surface area of cylindrical fruits (Zucchini) using digital image processing. Australian J. Crop Sci., 6(2), 1332-1336.

Bulent Koc A., 2007. Determination of watermelon volume using ellipsoid approximation and image processing. Postharvest Biol. Technol., 45, 366-371. https://doi.org/10.1016/j. postharvbio.2007.03.010

Chayjan R.A., Kaveh M., and Khayati S., 2017. Modeling some thermal and physical characteristics of terebinth fruit under semi industrial continuous drying. Food Measur., 11, 12-23. https://doi.org/10.1007/s11694-016-9366-4

Chen J., Lian Y., and Yaoming L., 2020. Real-time grain impurity sensing for rice combine harvesters using image processing and decision-tree algorithm. Comput. Electron Agric., 175, 105591.

https://doi.org/10.1016/j.compag.2020.105591

Curcio C., and Aversa M., 2014. Influence of shrinkage on convective drying of fresh vegetables: A theoretical model. J. Food Eng., 123, 36-49. https://doi.org/10.1016/j.jfoodeng.2013.09.014

Da Costa A.Z., Figueroa H.E.H., and Fracarolli J.A., 2020. Computer vision based detection of external defects on tomatoes using deep learning. Biosys. Eng., 190, 131-144. https://doi.org/10.1016/j.biosystemseng.2019.12.003

Demirbas H.Y. and Dursun I., 2007. Determination of some physical properties of wheat grains by using image analysis. Tarm Bilim. Der., 13 (3), 176-185.

Dursun E., and Dursun I., 2005. Some physical properties of caper seed. Biosys. Eng., 92(2), 237-245. https://doi. org/10.1016/j.biosystemseng.2005.06.003

Dziki D., and Laskowski J., 2005. Wheat Kernel physical properties and milling process. Acta Agrophysica, 6, 59-71.

El Fawal Y.A., Tawfik M.A., and El Shal A.M., 2009. Study on physical and engineering properties for grains of some field crops. Misr J. Ag. Eng., 26(4), 1933-1951. https://doi. org/10.21608/mjae.2009.107579
Forbes K., 2000. Volume estimation of fruit from digital profile image. M.Sc. Thesis Electronic Engineering, Cape Town.

Unal H.G., 2009. Some physical and nutritional properties of hulled wheat. Tarim Bilim. Derg., 15(1), 58-64. https://doi.org/10.1501/Tarimbil_0000001073

Jafari H., Kalantari D., and Azadbakht M., 2018. Energy consumption and qualitative evaluation of a continuous band microwave dryer for rice paddy drying. Energy, 142, 647654. https://doi.org/10.1016/j.energy.2017.10.065

Kalantari D., 2016. Grain flow from different discharge gates in a grain seeder. Eng. Agric. Environ. Food, 9, 141-146. https://doi.org/10.1016/j.eaef.2016.04.004

Kalantari D., and Eshtevad R., 2013. Influence of different tempering period and vacuum condition on the rice grain breakage. Cercetari Agronomic Moldava, 4(156), 5-13. https://doi.org/10.2478/v10298-012-0098-2

Kaveh M., Abbaspour-Gilandeh Y., Fatemi H., and Chen G., 2021. Impact of different drying methods on the drying time, energy, and quality of green peas. J. Food Process Preserv., 45(6): e15503. https://doi.org/10.1111/jfpp.15503

Kheiralipour K., Karimi M., Tabatabaeefar A., Naderi M., Khoubakht G., and Heidarbeigi K., 2008. Moisturedepend physical properties of wheat (Triticum aestivum L.). J. Agr. Technol., 4(1), 53-64.

Khojastehnazhand M., Omid M., and Tabatabaeefar A., 2008. Determination of tangerine volume using image processing. Int. J. Food Proper., 13(4), 760-770. https://doi.org/10.1080/10942910902894062

Khoshtaghaza M.H., and Chayjan R., 2007. Effect of some physical properties on fluidization stability of grain products. Biosys. Eng., 98(2), 192-197. https://doi.org/10.1016/j. biosystemseng.2007.08.004

Kiani M., Minaiei S., Maghsoudi H., and Ghasemi V.M., 2008. Moisture dependent physical properties of red bean (Phaseolus vulgaris L.) grains. Int. Agrophysics, 22, 231-237.

Mirasi A., Asoodar M.A., Samadi M., and Kamran E., 2014. The evaluation of wheat losses harvesting in two conventional combine (John Deere1165, 955) in Iran. Int. J. Advanc. Biolog. Biomed. Res., 2(5), 1417-1425.

Mohsenin N.N., 1978. Physical Properties of Plant and Animal Materials. Gordon Breach Science Publisher, New York, USA.

Munder S., Argyropoulos D., and Müller J., 2017. Class-based physical properties of air-classified sunflower seeds and kernels. Biosys. Eng., 164, 124-134. https://doi.org/10.1016/j.biosystemseng.2017.10.005

Mustafa C., 2007. Physical properties of barbunia bean seed. J. Food Eng., 80, 353-358. https://doi.org/10.1016/j. jfoodeng.2006.06.004

Narendra V.G., and Hareesh K.S., 2010. Prospects of computer vision automated grading and sorting systems in agricultural and food products for quality evaluation. Int. J. Computer Appl., 1, 0975- 8887. doi:10.5120/111-226

Navarro S. and Noyes R.T., 2002. The Mechanics and Physics of Modern Grain Aeration Management. CRC Press. https://doi.org/10.1201/9781420040333

Pourdarbani R., Sabzi S., Kalantari D., Hernández-Hernández J.L., and Arribas J.I., 2020. A computer vision system 
based on majority-voting ensemble neural network for the automatic classification of three chickpea varieties. Foods, 9(2), 113. https://doi.org/10.3390/foods9020113

Rashidi M., Seyfi K., and Gholami-Parashkouhi M., 2007. Determination of kiwifruit volume using image processing. ARPN J. Agr. Biolog. Sci., 2(6): 17-22.

Razavi M.A., and Akbari R., 2011. Biophysical properties of agricultural crops and food materials. Ferdowsi University of Mashad Publications, 39-47.

Sabzi S., Pourdarbani R., Kalantari D., and Panagopoulos T., 2020. Designing a fruit identification algorithm in orchard conditions to develop robots using video processing and majority voting based on hybrid artificial neural network. Appl. Sci., 10(1), 383. https://doi.org/10.3390/app10010383

Sadrnia H., Rajabipour A., Jafary A., Javadi A., and Mostofi Y., 2007. Classification and analysis of fruit shapes in long type watermelon using image processing. Int. J. Agr. Biolog., 1, 68-70.

Saini M., Singh J., and Prakash N.R., 2012. Analysis of wheat grain varieties using image processing-A Review. Int. J. Sci. Res., 3(6), 490-495.

Shkelqim K., and Joachim M., 2010. Determination of physical, Mechanical and chemical properties of seeds and kernels of (Jatropha curcas L.). Int. Crop. Prod., 32(2), 129-138. https://doi.org/10.1016/j.indcrop.2010.04.001
Solomon W.K., and Zewdu A.D., 2009. Moisture-dependent physical properties of niger (Guizotia abyssinica Cass.) seed. Int. Crop. Prod., 29, 165-170. https://doi.org/10.1016/j. indcrop.2008.04.018

Tabatabaeefar A., 2003. Moisture-dependent physical properties of wheat. Int. Agrophysics, 17, 207-211.

Varnamkhasti M.G., Mobli H., Jafari A., Soltanabadi M.H., Rafiee S., and Sadeghi R., 2007. Some physical properties of rough rice (Oryza sativa L.) grain. J. Cereal Sci., 47(3), 496-501. https://doi.org/10.1016/j.jcs.2007.05.014

Vongpradubchai S., and Rattanadecho P., 2009. The microwave processing of wood using a continuous microwave belt dryer. J. Chem. Eng., Process: Process Int., 48, 9971003. https://doi.org/10.1016/j.cep.2009.01.008

Wang T.Y., and Nguang S.K., 2007. Low cost sensor for volume and surface area computation of axisymmetric agricultural products. J. Food Eng., 79, 870-877. https://doi.org/10.1016/j.jfoodeng.2006.01.084

Xie W., Wang F., and Yang D., 2019. Research on carrot surface defect detection methods based on machine vision. IFACPapers on Line, 52(30), 24-29. https://doi.org/10.1016/j. ifacol.2019.12.484

Zayas I., Lai F.S., and Pomeranz Y., 1986. Discrimination between wheat classes and varieties by image analysis. J. Cereal Chem., 63(1), 52-56. 